Optimal Allocation of Land for Training and Non-training Uses (OPAL)

\title{
Initial Effects of Heavy Vehicle Trafficking on Vegetated Soils
}

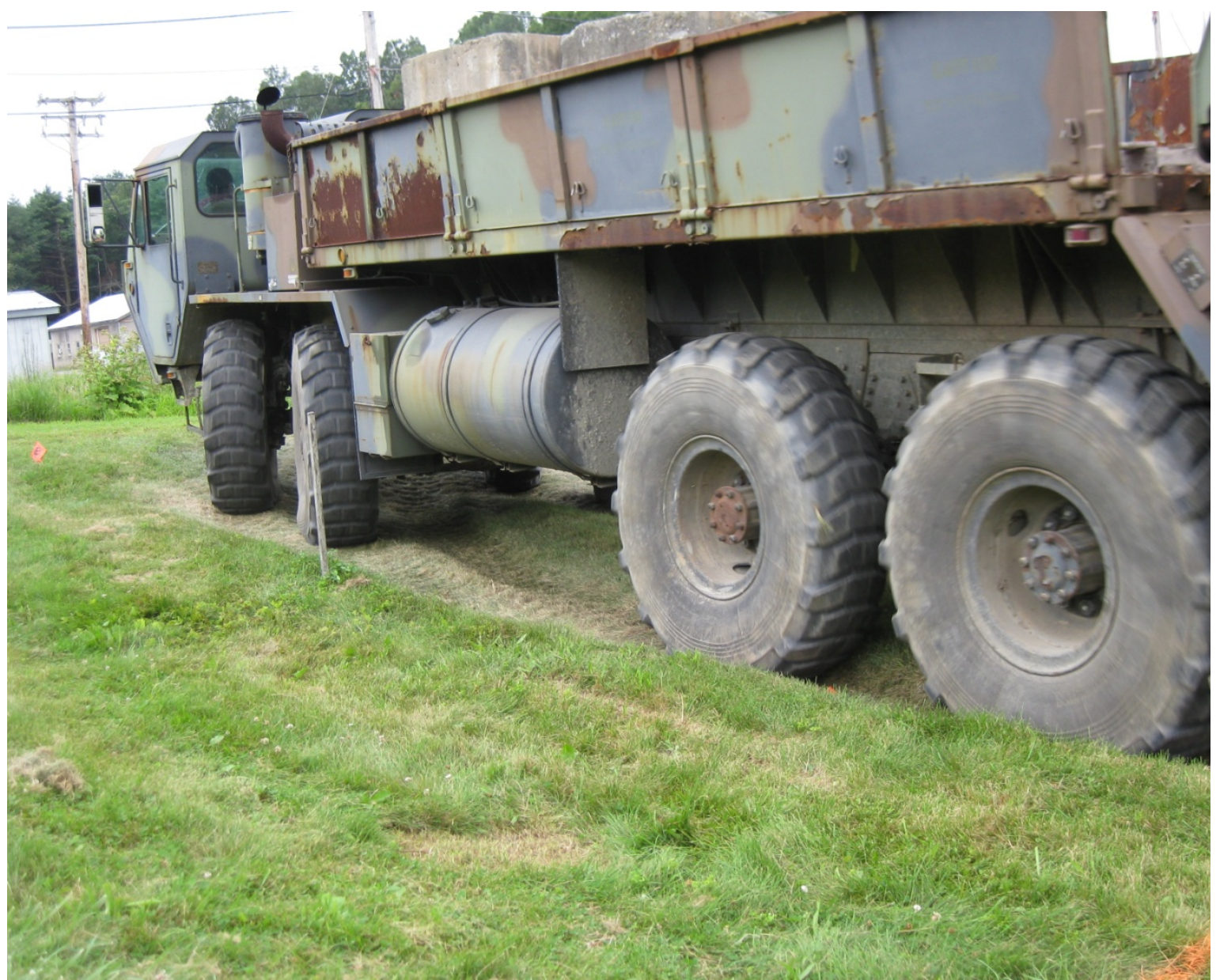


Front Cover: Rut formation due to heavy vehicle trafficking of the outdoor loam test section. 


\section{Initial Effects of Heavy Vehicle Trafficking on Vegetated Soils}

Nicole L. Buck, Sally A. Shoop, and Timothy J. Cary

Cold Regions Research and Engineering Laboratory

U.S. Army Engineer Research and Development Center

72 Lyme Road

Hanover, NH 03755

Final report

Approved for public release; distribution is unlimited.

Prepared for U.S. Army Corps of Engineers

Washington, DC 20314-1000 


\section{Abstract}

Numerous studies have investigated the effects of vehicle trafficking on terrain and how soils and soil conditions affect the mobility of military vehicles. However, the majority of these studies were conducted on nonvegetated soils. The purpose of our four-year study is to investigate the effects of heavy vehicle trafficking on vegetated soils and to assess the impacts of vegetation, specifically grass, on vehicle mobility. The research program includes a series of experiments assessing the effects of trafficking, mowing, and burning on vegetated soil strength. Three test sections were constructed and planted with perennial ryegrass: one section represented outdoor field conditions and two were controlled indoor sections (sand and silty loam). Mobility parameters of motion resistance and traction were collected in each test section prior to trafficking by a large military vehicle (HEMTT). Before and after trafficking, each test section was characterized including soil strength, moisture content, soil density, and terrain disturbance. The results show that vegetation affects soil strength and thus the terrain impacts of trafficking. Additionally, treatment of the vegetation affects soil strength, especially in silty loam soils. This paper summarizes the first year results regarding soil condition, soil strength, and vehicle impact severity. Future years will assess the recovery of the vegetation in the tested areas with the ultimate goal of making recommendations for the treatment of vegetated military training lands. 


\section{Table of Contents}

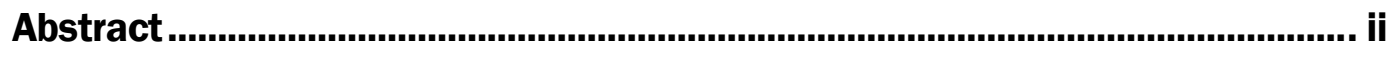

List of Figures and Tables ..........................................................................................

Preface (.....................................................................................................

Acronyms................................................................................................................

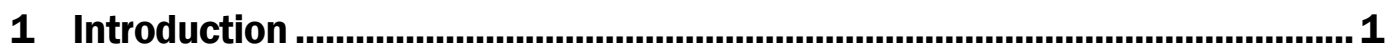

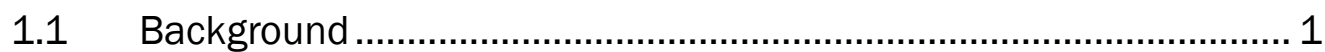

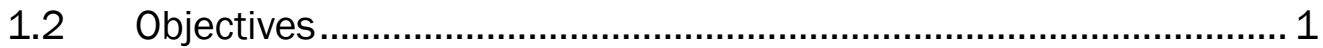

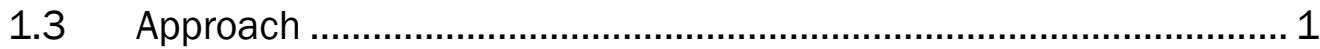

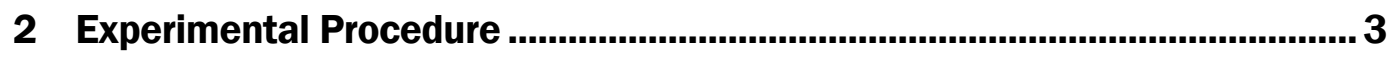

2.1 Test sections and construction .................................................... 3

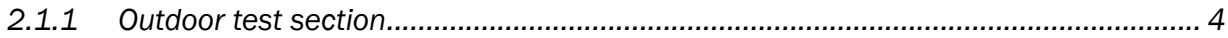

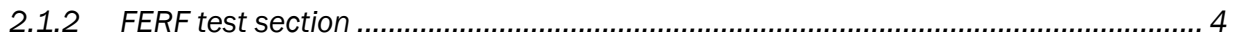

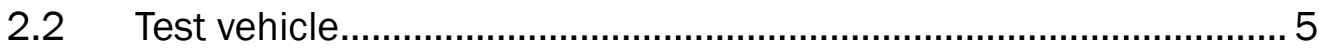

2.3 Terrain measurements ............................................................. 6

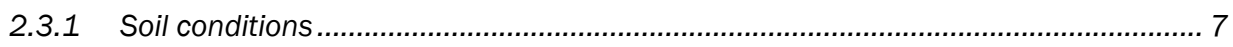

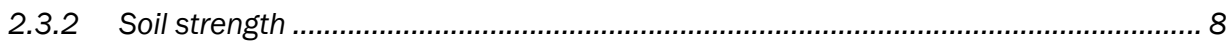

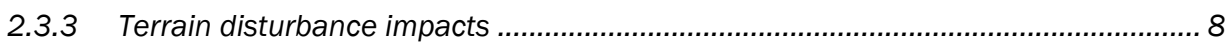

3 Results and Discussion ........................................................................11

3.1 Soil conditions......................................................................... 11

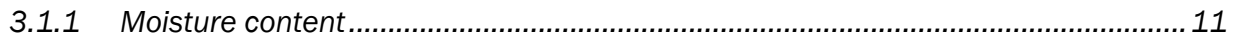

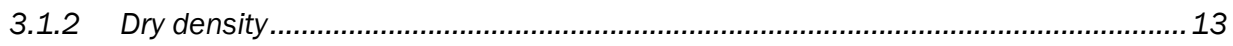

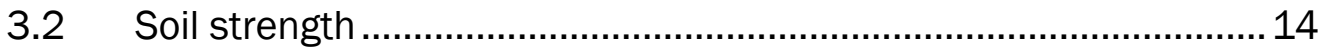

3.2.1 Outdoor test section.................................................................................... 14

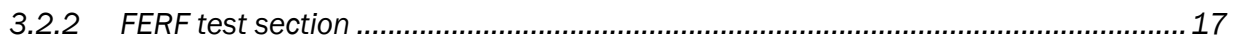

3.3 Terrain disturbance............................................................... 19

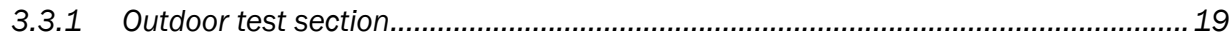

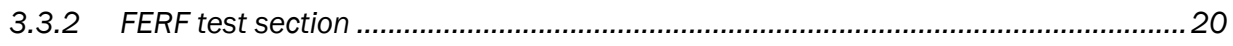

4 Conclusions …........................................................................................................23

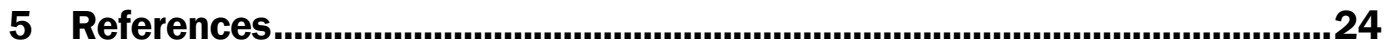

Appendix A: Profilometer Analysis MATLAB Code ............................................25 


\section{List of Figures and Tables}

\section{Figures}

Figure 1. Outdoor test section. .......................................................................

Figure 2. View of FERF test section ...................................................................

Figure 3. Heavy Expandable Mobility Tactical Truck (HEMTT) ..................................6

Figure 4. Profilometer used to measure the disturbance profile..............................

Figure 5. Near-surface volumetric moisture content measured by three sampling techniques in the outdoor test section ................................................. 11

Figure 6. Moisture contents of test soils prior to trafficking (dotted lines) and post-trafficking ........................................................................................... 12

Figure 7. Comparison of dry density measurements using nuclear gauge and drive cylinder techniques at the surface for the outdoor test section. .......... 13 Figure 8. Dry density versus depth for all test sections and treatments. In all cases, density increases after trafficking........................................................14

Figure 9. Strength indices for outdoor loamy sand. ............................................ 15

Figure 10. Cone index soil strength profiles for the outdoor unmowed and mowed test sections ...........................................................................................17

Figure 11. Strength indices for the FERF test sections........................................ 18

Figure 12. Shear strength for the FERF test sections. ......................................... 19

Figure 13. Outdoor section impact severity index results...................................... 19

Figure 14. Outdoor loam rut depths and pile heights .......................................... 20

Figure 15. FERF Section impact severity index results. ........................................21

Figure 16. FERF rut depths and pile heights...................................................... 22

\section{Tables}

Table 1. Test section construction and trafficking summary....................................

Table 2. Summary of soil specifications. ................................................................3

Table 3. Number and type of terrain measurements collected in each treatment area before, during, and after vehicle trafficking. ....................................

Table 4. Modified recovery impact severity guidelines for seasonal terrain ..........10 


\section{Preface}

The research work described in this report was funded by the U.S. Army Corps of Engineers Engineering Research and Development Center, Optimal Allocation of Land for Training and Non-Training Uses (OPAL) Program. The work was conducted by Nicole Buck and Sally Shoop of the Force Projection and Sustainment Branch (RR-H), and Timothy Cary of the Biogeochemical Sciences Branch (RR-N). The work was performed under the guidance of Ms Heidi Howard (CERL) as the Program Manager and Dr. Alan Anderson (CERL) as the Technical Director, Military Ranges and Lands. Construction, trafficking, and measurements of the test sections were conducted by a research team that included Lynette Barna, Charles Smith, Jesse Stanley, Kelley MacDonald, Michael Diamond, Bruce Allen, Chris Berini, Trudy Fadden, Jen Helble, and Corey Tillson, all staff members of the Research and Engineering Division, U.S. Army Engineer Research and Development Center - Cold Regions Research and Engineering Laboratory (ERDC-CRREL). At the time of publication, Dr. Edel Cortez was Branch Chief, CEERD-RR-H; Dr. Justin Berman was Division Chief, CRREL-RR. The Deputy Director of ERDC-CRREL was Dr. Lance Hansen and the Director was Dr. Robert E. Davis.

COL Kevin Wilson was the Commander and Executive Director of ERDC, and Dr. Jeffery Holland was the Director. 


\section{Acronyms}

FERF Frost Effects Research Facility

HEMTT Heavy Expanded Mobility Tactical Truck

HH2 Capacitance-based soil moisture probe

USCS Unified Soil Classification System

USDA United States Department of Agriculture 


\section{Introduction}

\subsection{Background}

In 2004, the Army introduced "The Army Strategy for the Environment: Sustain the Mission, Secure the Future." This document highlights the Army's desire to shift from a compliance-driven environmental strategy to a sustainability-based strategy. By shifting the focus to sustainability, the Army aims to ensure use of training land resources into the future. An important component of military training is trafficking. Trafficability is the ability of land to sustain vehicle traffic. Although numerous studies of trafficability have been conducted on natural soils, their results do not have suitable information to support all land management decisions (Anderson et al. 2005). A sustainable approach to managing training lands will need to include methods to evaluate trafficked lands.

\subsection{Objectives}

The objective of this four-year study is to determine the immediate effects of trafficking on multiple land management strategies including unmanaged grass swards, mowed or grazed grasslands, and controlled burning of grasslands compared to bare soil. This was achieved through controlled field and laboratory experiments designed to assess the impacts of trafficking on soil conditions and soil strength. Results of the first year's efforts described in this report will be used to develop algorithms to provide a better understanding of the trafficability of Army-managed training lands. These results will also be used with future data to relate disturbed soil characteristics to biomass production, to determine how land management treatments affect soil recovery after military vehicle trafficking, and to update algorithms in the NATO Reference Mobility Model. The primary objective of this year one study is to develop relationships between heavy vehicle trafficking and vegetated soil strength.

\subsection{Approach}

Experiments were designed to determine the immediate impacts of vehicle trafficking on vegetated soils subjected to multiple land management treatments. Biomass, specifically above ground plants and below ground roots, is expected to improve the soil's resistance to trafficking. The primary goal in designing this set of experiments is to determine the impacts of 
vehicle trafficking on soil strength and biomass after individual passes and multiple passes to the point of soil failure. Observations of terrain impact, soil conditions, soil strength, and biomass production, compared with vehicle mobility parameters in different soil types provide good indicators to the effectiveness of each land management treatment in sustaining vehicle traffic. This paper focuses on the effects of heavy military vehicle trafficking on soil parameters that control biomass production (soil conditions, soil strength, and terrain impacts) within different land management treatments. Vehicle mobility and biomass results are investigated in separate papers. 


\section{Experimental Procedure}

\subsection{Test sections and construction}

Tests were conducted in two locations on the CRREL campus in Hanover, New Hampshire: outside and inside within the Frost Effects Research Facility (FERF). Table 1 summarizes the construction and trafficking of the test sections. Table 2 provides a summary of the soil specifications for each test section.

Table 1. Test section construction and trafficking summary.

\begin{tabular}{|l|l|l|}
\hline Category & Outdoor & FERF \\
\hline Total Size & $7.3 \mathrm{~m} \times 21 \mathrm{~m}$ & $4.6 \mathrm{~m} \times 24.4 \mathrm{~m}$ \\
\hline Vegetation & $\begin{array}{l}\text { Perennial Rye Grass Mix } \\
\text { (Primarily with Clover) }\end{array}$ & Perennial Rye Grass \\
\hline $\begin{array}{l}\text { Grass Treatments (\# of } \\
\text { treatments per soil type) }\end{array}$ & Mowed, unmowed & $\begin{array}{l}\text { Bare soil (trafficked-only), } \\
\text { unmowed, mowed, and } \\
\text { burned }\end{array}$ \\
\hline Soil type & Charlton Loamy Sand & Fine Sand; Silty Loam \\
\hline Trafficking & HEMTT (3 Aug 2010) & HEMTT (12 Aug 2010) \\
\hline No. of passes to failure & 100 & 10 \\
\hline
\end{tabular}

Table 2. Summary of soil specifications.

\begin{tabular}{|l|c|c|c|}
\hline \multicolumn{1}{|c|}{ Category } & Outdoor Loam & FERF Sand & FERF Loam \\
\hline USCS/ USDA Classification & SM/Loamy Sand & SP/Fine Sand & CL/Silty Loam \\
\hline \% Gravel or greater & 0.7 & 1.9 & 0.0 \\
\hline \% Coarse sand & 5.1 & 13.9 & 2.5 \\
\hline \% Medium sand & 40.1 & 44.7 & 4.8 \\
\hline \% Fine sand & 31.6 & 36.1 & 9.9 \\
\hline \% Fines & 22.5 & 3.4 & 46.9 (silt) \\
\hline Liquid Limit/Plastic Limit & -- & -- & $27 / 18$ \\
\hline
\end{tabular}




\subsubsection{Outdoor test section}

The outdoor section was underlain by Loamy Sand soil, consisting of a poorly graded medium to fine sand with silt. The section had two treatments: mowed grass and unmowed grass. Its vegetative cover was Perennial Rye grass mixed primarily with Clover. The section had been vegetated several years prior to trafficking and was thus well established. The test section is $7.3 \mathrm{~m}$ wide and $21 \mathrm{~m}$ long, with $10 \mathrm{~m}$ of unmowed grass and $11 \mathrm{~m}$ of mowed grass for treatments (Fig. 1). Grass in the unmowed section reached a height of approximately $0.5 \mathrm{~m}$. The test vehicle was driven straight through the section except for the last $5.5 \mathrm{~m}$ of the mowed grass treatment, which was the turning zone, also referred to as the shear zone.

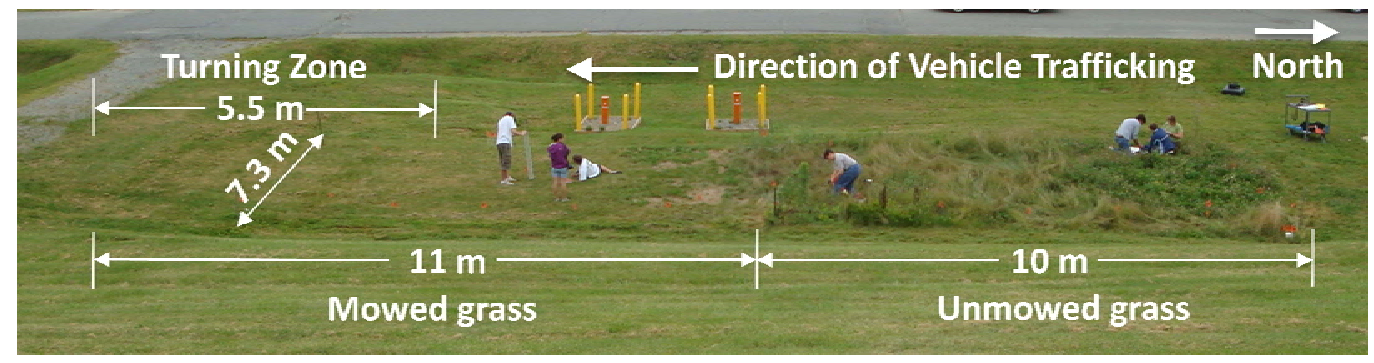

Figure 1. Outdoor test section. Test vehicle travels straight from North (right) to South across two treatments, mowed and unmowed grass, then turns in the last $5.5 \mathrm{~m}$ of the test section.

\subsubsection{FERF test section}

Test sections for this study were constructed on the west side of the FERF over a two-month period and allowed to mature over four months. Other test sections were also constructed on the east side that were intended for use in a separate study. Artificial growing conditions were simulated in the FERF through temperature control, growth lights, and twice-weekly watering. The $4.5-\mathrm{m}$ wide by $24.4-\mathrm{m}$ long test section is split into two equal halves by soil type: a poorly graded sand with silt and a clay-rich silty loam. To replicate a natural field setting, the test section soils were minimally compacted when installed. The test section was planted with Perennial Rye grass and divided into four treatments (each $3 \mathrm{~m}$ in length) within each soil type: trafficked only (no vegetation), unmowed grass, mowed grass, and burned grass (Fig. 2). A 1-m transition zone separated the loam and sand soils. Grass in the unmowed treatment areas reached a height of approximately $15 \mathrm{~cm}$. Shoop et al. (2010) describe additional details on the test sections' construction. The trafficked-only section was originally intended to be bare soil, but grass grew in that section. To remedy this, grass in the trafficked-only section was treated with glyphosate and raked prior 
to the experiments. The test vehicle traveled from North to South, crossing the silty loam test section first before transitioning to the sand soil test section.

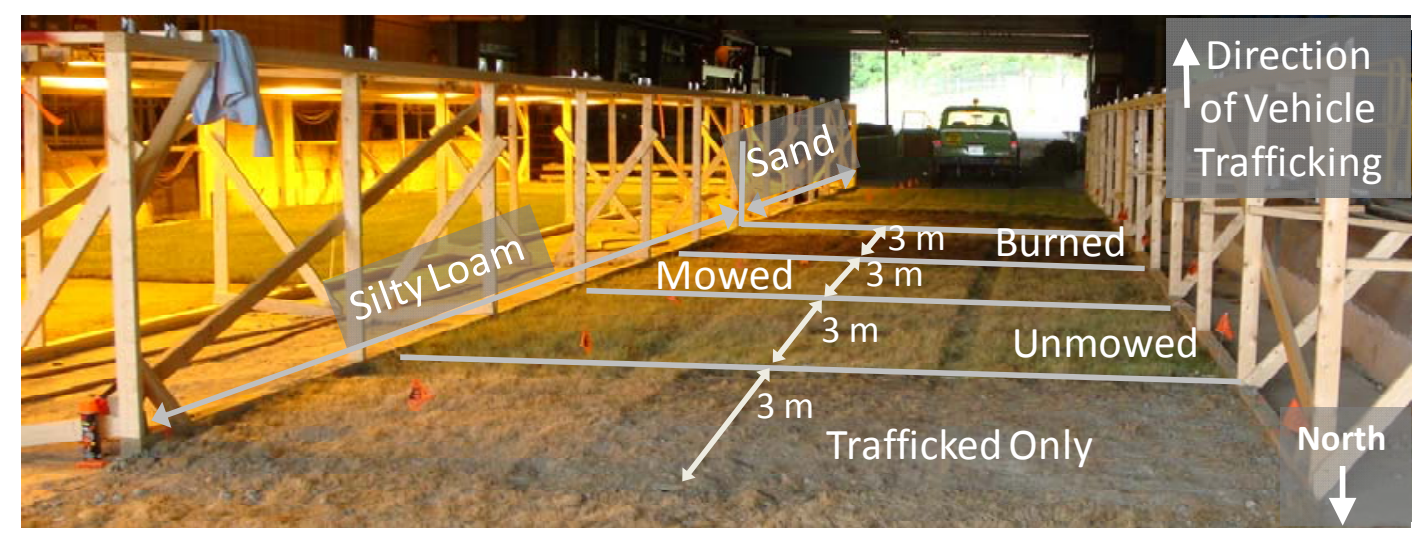

Figure 2. View of FERF test section. Test vehicle travels from North (foreground) to South across eight 3-m test sections: trafficked only, and unmowed, mowed, and burned grass in two soil types: silty loam and sand. Vehicle shown is the CRREL Instrumented Vehicle.

\subsection{Test vehicle}

Prior to trafficking, the CRREL Instrumented Vehicle was used to obtain mobility parameters (such as motion resistance and traction). The mobility parameters will be summarized in a complementary paper.

The primary vehicle trafficking was conducted with a large off-road military vehicle known as a Heavy Expanded Mobility Tactical Truck (HEMTT 977). The HEMTT is an $8 \times 8$ vehicle with a 61-cm (24-in.) ground clearance that is steered with the front two axles (Fig. 3). The gross vehicle weight of this HEMTT was $18,257 \mathrm{~kg}(40,250 \mathrm{lb})$ and it was loaded with an additional $4717 \mathrm{~kg}(10,400 \mathrm{lb})$ payload. The $16.00 \mathrm{R} \times 20$ tires were run at the pressure specified for cross-country operations: $241 \mathrm{kPa}$ (35 psi) on the two front axles and $276 \mathrm{kPa}(40 \mathrm{psi})$ on the two rear axles. 


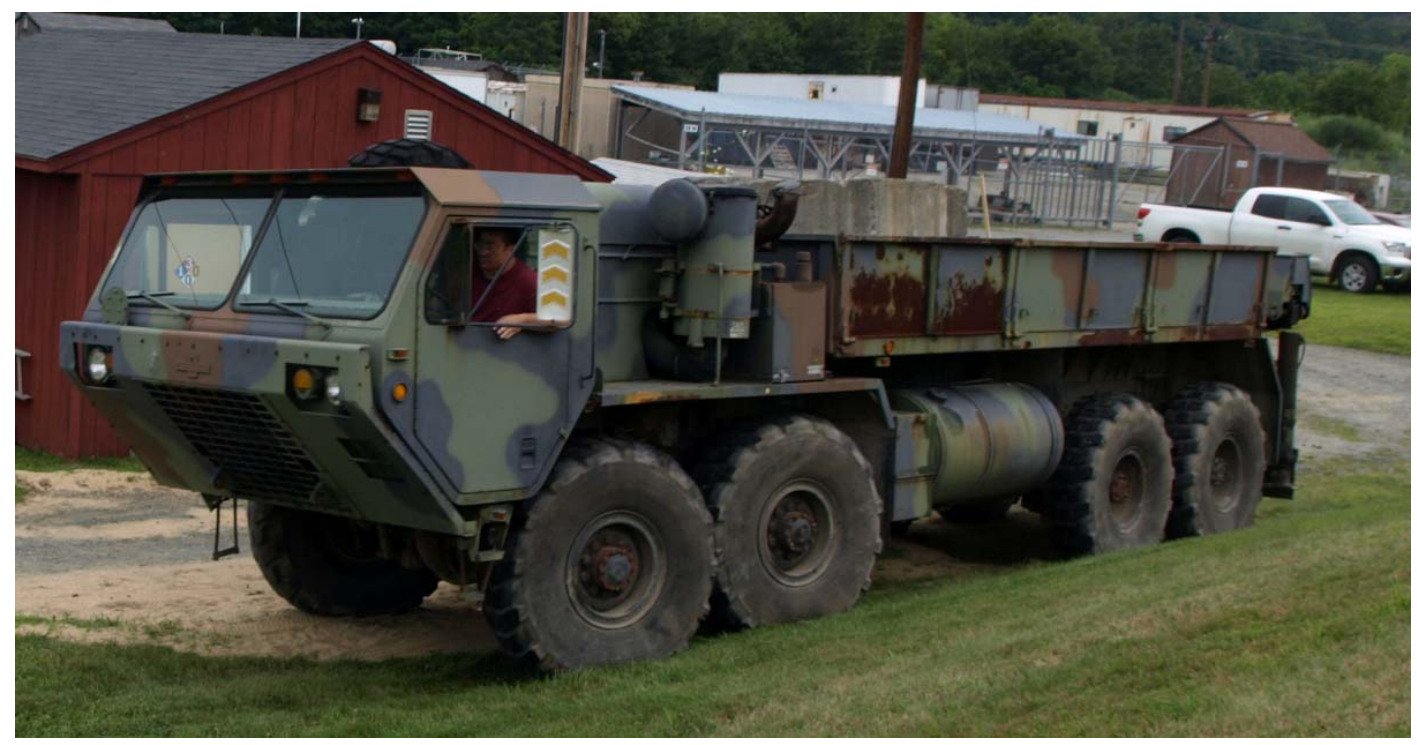

Figure 3. Heavy Expandable Mobility Tactical Truck (HEMTT). This $8 \times 8$ vehicle is steered with the two front axles with a total vehicle weight of $23,000 \mathrm{~kg}$ including payload.

\subsection{Terrain measurements}

Determining the impact of trafficking on vegetated soil required a variety of terrain measurements including soil conditions, soil strength, and terrain disturbance. Prior to trafficking, the test section soils were characterized to obtain the initial soil conditions and soil strength. Intermittently during the experiments, the impacts of trafficking were visually examined to assess the level of damage to the terrain. In the outdoor section, 100 passes were completed before portions of the test section showed substantial damage (contact patch compaction and shearing along the sides of the ruts) due to the heavy vehicle. Soil strength was assessed after 10, 25, 50, and 75 passes; the full suite of soil tests was completed at 100 passes. Since the FERF section was less compacted and less well established than the outdoor section, only 10 passes were completed before portions of the section showed substantial damage. Soil strength was assessed after five passes and the full suite of terrain measurement tests was completed after 10 passes.

Table 3 shows a portion of the terrain measurements collected during the experiments. To readily compare soil types and vegetation treatments, the measurements in each treatment were averaged and the standard error was calculated. 
Table 3. Number and type of terrain measurements collected in each treatment area before, during, and after vehicle trafficking.

\begin{tabular}{|c|c|c|c|c|c|c|}
\hline \multirow[t]{2}{*}{ Measurement } & \multicolumn{3}{|c|}{ Outdoor Section } & \multicolumn{3}{|c|}{ FERF Section } \\
\hline & $\begin{array}{l}\text { Prior to } \\
\text { Trafficking }\end{array}$ & $\begin{array}{l}\text { Intermittent } \\
\text { Passes }\end{array}$ & $\begin{array}{l}\text { Post } \\
\text { Trafficking }\end{array}$ & $\begin{array}{l}\text { Prior to } \\
\text { Trafficking }\end{array}$ & $\begin{array}{l}\text { Intermittent } \\
\text { Passes }\end{array}$ & $\begin{array}{l}\text { Post } \\
\text { Trafficking }\end{array}$ \\
\hline Pass Numbers & - & $10,25,50,75^{a}$ & 100 & - & 5 & 10 \\
\hline \multicolumn{7}{|l|}{ Soil Conditions } \\
\hline $\begin{array}{l}\text { Nuclear Gauge } \\
\text { (Moisture and } \\
\text { Density) }\end{array}$ & 5 & - & $2,6^{b}$ & 1 & - & 1,2 \\
\hline Drive Cylinders & 5 & - & 4,6 & - & - & - \\
\hline $\mathrm{HH} 2$ & 5 & - & 4,6 & - & - & - \\
\hline \multicolumn{7}{|l|}{ Soil Strength } \\
\hline $\begin{array}{l}\text { Cone } \\
\text { Penetrometer }\end{array}$ & 5 & 2 & 0,6 & 6 & - & 4 \\
\hline $\begin{array}{l}\text { Clegg Impact } \\
\text { Hammer }\end{array}$ & 5 & 2 & 0,6 & 4 & 4 & 4 \\
\hline Drop Cone & 5 & 2 & 2,6 & 4 & 4 & 4 \\
\hline Pilcon (surface) & 5 & 2 & 4,6 & 4 & 4 & 4 \\
\hline Pilcon (9cm) & 5 & - & 4,6 & - & - & - \\
\hline \multicolumn{7}{|c|}{ Terrain Disturbance } \\
\hline Profilometer & - & 6 & 0,6 & - & 4 & 4 \\
\hline Severity Index & - & - & 1,1 & - & - & 1 \\
\hline \multicolumn{7}{|c|}{$\begin{array}{l}\text { a. The only measurements collected at } 10 \text { passes were by the Clegg Impact Hammer and Drop Cone. The } \\
\text { Clegg was repeated at } 25 \text { passes, but the Drop Cone was not measured at } 25 \text { passes. } \\
\text { b. The first number refers to the number of measurements taken in the turning zone; the second number } \\
\text { refers to the number of measurements taken in the straight test sections. }\end{array}$} \\
\hline
\end{tabular}

\subsubsection{Soil conditions}

To characterize the effects of trafficking on soil conditions, measurements of soil moisture and density were collected before and after trafficking; a few moisture samples were also taken during trafficking. Soil moisture was obtained via several methodologies, including:

- a capacitance-based soil moisture probe (HH2 by Dunamax),

- soil moisture determined on a weight basis using samples collected with small drive cylinders near the surface $(1-6 \mathrm{~cm})$ and at a depth of approximately 7-12 $\mathrm{cm}$, and

- a nuclear gauge using both surface backscatter and profile mode every $5 \mathrm{~cm}$ down to a depth of $30 \mathrm{~cm}$. 
The capacitance-based soil moisture probe and nuclear-based nuclear gauge provide volumetric soil moisture measurements. Gravimetric soil moisture measurements were obtained using drive cylinders. These measurements were later converted to volumetric moisture content. Soil density was also collected using the drive cylinders and a nuclear gauge at the same depths as for soil moisture.

\subsubsection{Soil strength}

Soil strength measurements provide an indication of the soil's ability to handle trafficking. Although soil strength measurements were obtained at both the surface and at depth, we focused on the top $15 \mathrm{~cm}$ where the greatest influence on vehicle mobility and trafficability is observed (Shoop et al. 2010). A standard trafficability cone penetrometer was used before and after trafficking up to a depth of $30 \mathrm{~cm}$. Surface compaction strength was obtained using the Clegg Impact Hammer with a 2.25-kg drop weight. A dynamic drop cone designed by Goodwin (1991) was used to provide an index of surface soil strength. The dynamic drop cone has been correlated with soil moisture, shear strength, and wheel rut depth (Goodwin 1991). A Pilcon shear vane was used to obtain shear samples before, during, and after trafficking in the wheel path at the surface and at a depth of 7-8 cm in the outdoor test section; measurements were collected in the rut walls in the FERF test sections.

\subsubsection{Terrain disturbance impacts}

Vehicle rut and disturbance profiles provide an easy measurement of terrain disturbance due to vehicle trafficking. Terrain disturbance was assessed by determining the maximum rut depth and pile height. Rut profiles were obtained using a profilometer, which consists of a 1.25-m metal frame holding 59 fiberglass rods spaced every $2 \mathrm{~cm}$ horizontally and marked every $1 \mathrm{~cm}$ vertically (Fig. 4). To collect measurements, the profilometer is carefully centered in the rut such that the rods are touching the soil surface. An image of the profilometer is then acquired showing the profile of the rut. The images are processed in the program MATLAB ${ }^{\circledR 1}$ using a script (Appendix A) that allows the user to quickly trace the rut profile and outputs the maximum rut depth and pile height in engineering units. The rut depth and pile height provide a reasonable indication of the impact severity.

1 The MathWorks, Inc. Natick, MA 


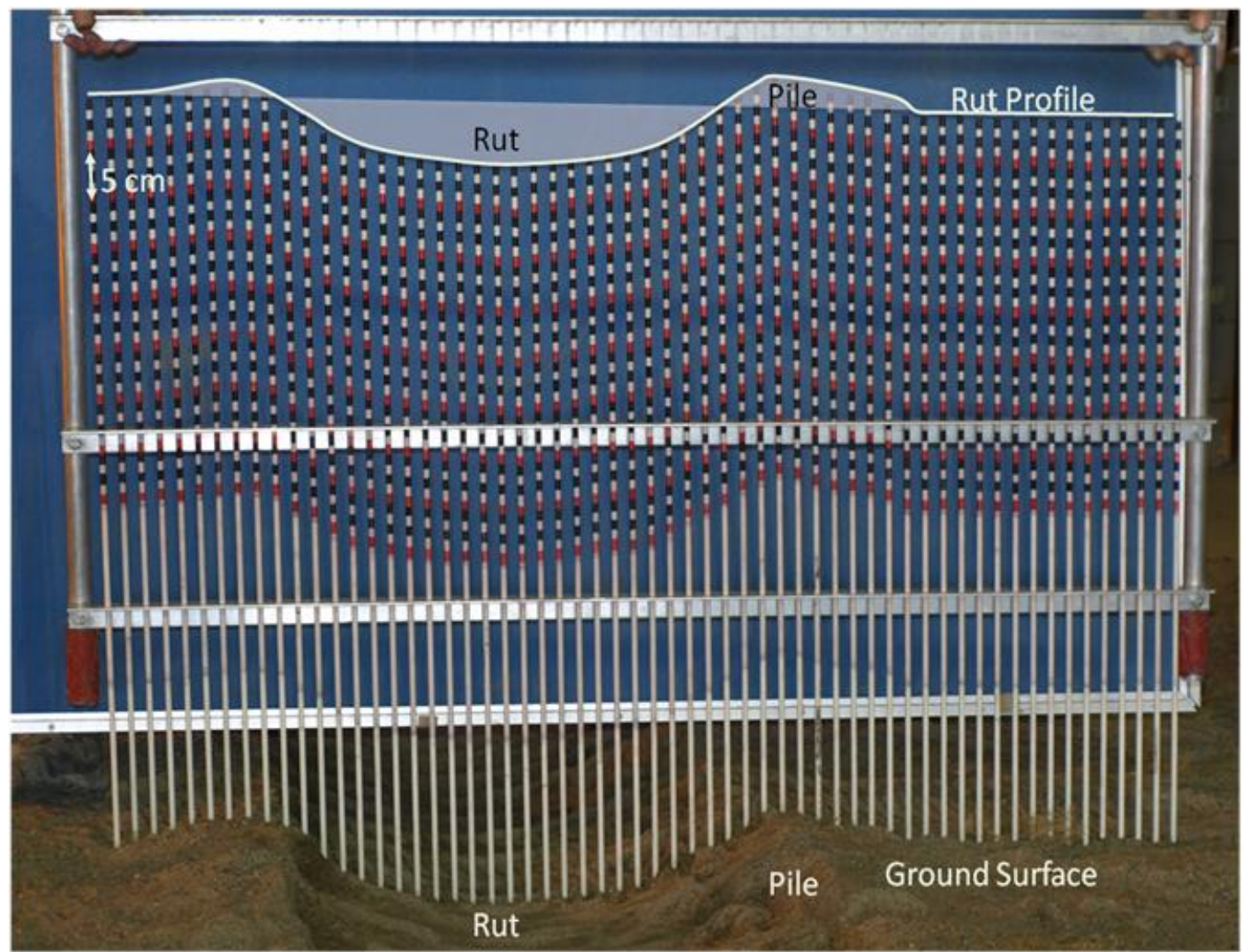

Figure 4. Profilometer used to measure the disturbance profile. The device documents maximum rut depth and pile height in centimeters for each sampling location.

The type of vehicle disturbance can be classified using the following categories from Haugen et al. (2002):

- Imprint-compressed soil and vegetation in the vehicle track.

- Scrape-soil and vegetation that has been stripped away from the vehicle track.

- Combination-a combination of a scrape and an imprint that does not specifically fit into one of those classifications.

- Pile-soil and vegetation that has been piled at the edge of the vehicle track.

The impact severity was also assessed for the ruts according to a methodology developed by Haugen et al. (2002) and modified by Affleck (2005). The impact severity is the percentage of vegetation or soil that has been damaged, moved, or removed by the vehicle according to the guidelines in Table 4 . 
Table 4. Modified recovery impact severity guidelines for seasonal terrain (from Affleck 2005; modified from Haugen et al. 2002).

\begin{tabular}{|l|l|}
\hline $\begin{array}{l}\text { Impact } \\
\text { Severity (\%) }\end{array}$ & Guidelines \\
\hline 0 & $\begin{array}{l}\text { No visible disturbance as compared to surrounding vegetation/area; no } \\
\text { depression of vehicle track or rutting }\end{array}$ \\
\hline 10 & $\begin{array}{l}\text { Slight leaning of vegetation; vegetation may be leaning in the direction of the } \\
\text { vehicle track instead of standing straight compared to surrounding vegetation; } \\
\text { depression of vehicle track or rutting still exist [ } 5.6 \mathrm{~cm} \text { (3 in.)] but vegetation } \\
\text { cover similar or same in size as surrounding vegetation; vehicle track only } \\
\text { slightly visible }\end{array}$ \\
\hline 20 & $\begin{array}{l}\text { Leaning of vegetation, likely in the direction of vehicle tracking compared to } \\
\text { surrounding vegetation; depression of vehicle track or rutting still exist but } \\
\text { vegetation cover similar in size as surrounding vegetation; visibility of tracks; } \\
\text { little to no disturbance of soil visible }\end{array}$ \\
\hline 40 & $\begin{array}{l}\text { Depression of vehicle track narrowing and more shallow due to soil slumping, } \\
\text { movement or erosion; bare soil visible; over one third of the vegetation not } \\
\text { present compared to surrounding; vegetation growing in track not as fully grown } \\
\text { or as large as surrounding vegetation or other vegetation types growing along } \\
\text { the tracks (e.g. moss); if rocky soil, some rock visible in bare soil; organic matter } \\
\text { accumulating in tracks }\end{array}$ \\
\hline 60 & $\begin{array}{l}\text { About one third of the area with growing vegetation; vegetation smaller than } \\
\text { surrounding vegetation or sign of other vegetation types growing along the } \\
\text { tracks (e.g. moss, dominant or invasive vegetation); significant amount of bare } \\
\text { soil still exposed; if rocky soil, rocks visible on soil surface; depression of track } \\
\text { visible; sign of soil slumping, movement or erosion in tracks }\end{array}$ \\
\hline 80 & $\begin{array}{l}\text { Few vegetative species growing on vehicle path; vegetation present is much } \\
\text { smaller and less developed than surrounding vegetation; depression of track } \\
\text { visible; if in a rocky soil, increasing amount of rocks visible in track }\end{array}$ \\
\hline $\begin{array}{l}\text { Track is bare soil with no vegetation growing; depression of track visible; if in a } \\
\text { rocky soil, rocks highly visible in track }\end{array}$ \\
\hline 100
\end{tabular}




\section{Results and Discussion}

\subsection{Soil conditions}

\subsubsection{Moisture content}

An analysis of the soil moisture measurements collected with the three sampling techniques [nuclear gauge; capacitance-based probe (HH2); drive cylinder] shows they provide similar values. This is demonstrated in Figure 5, which presents data from the near-surface (top 5-8 cm) using all three techniques taken at the outdoor test section before and after trafficking. Given the similarity in results, the nuclear gauge was chosen as the preferred method for obtaining soil moisture measurements as it provides readings at multiple depths and simultaneously measures dry density data. Figure 5 also shows the difference in average volumetric moisture content for each area before and after trafficking. In the unmowed grass section, moisture content did not change significantly; in the mowed grass section, however, moisture content increased after trafficking. Given the variability of the data in the turning (shear) zone, it is difficult to assess the impact of trafficking on the soil moisture content in that section.

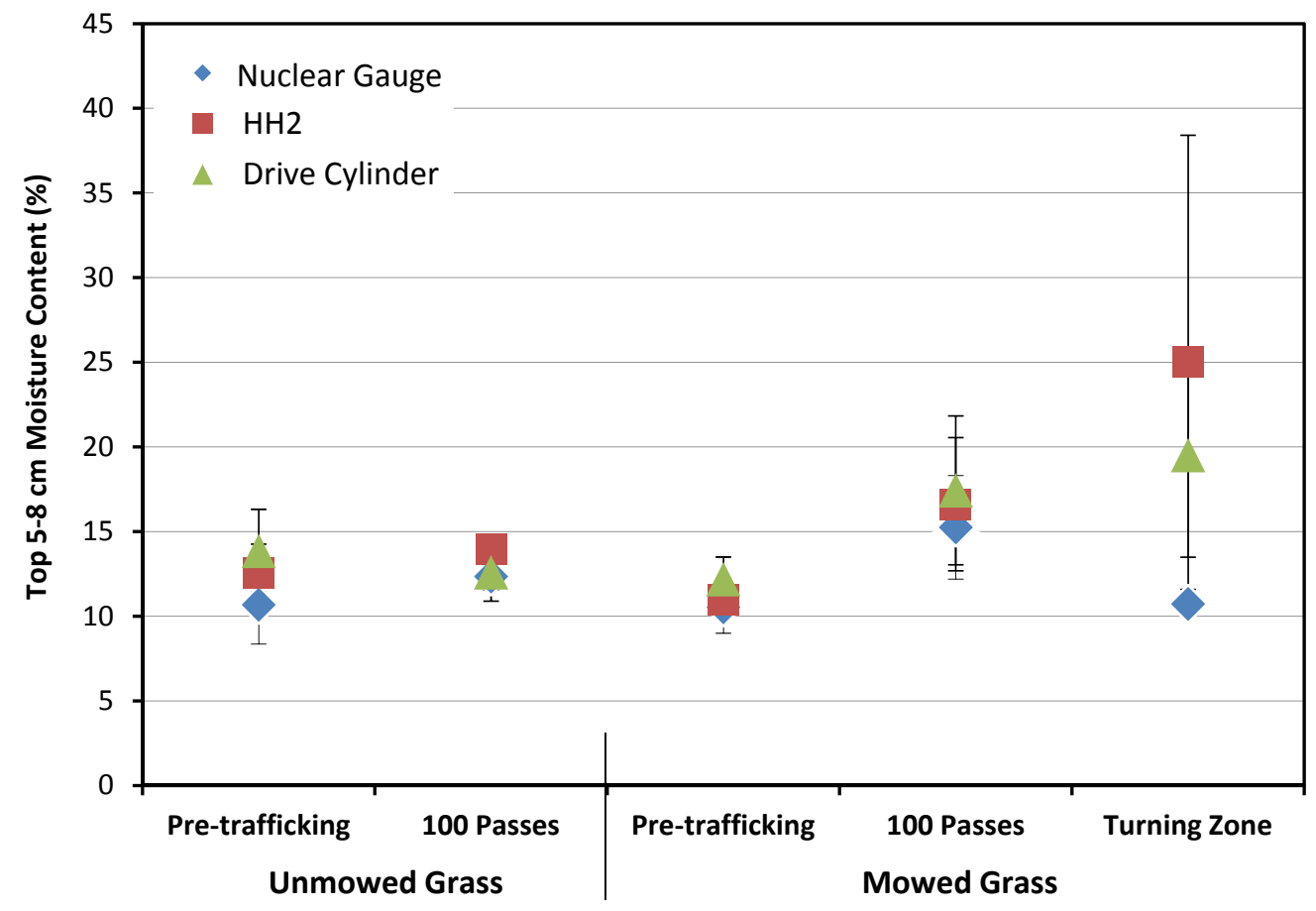

Figure 5. Near-surface volumetric moisture content measured by three sampling techniques in the outdoor test section. Error bars indicate one standard deviation. 
Moisture contents at depth for the outdoor loamy sand and FERF silty loam soils increased with trafficking; on the other hand, moisture content decreased after trafficking in the FERF sand soil (Fig. 6). The slight decrease in moisture content for the sand may be due to the time delay (approximately 24 hours) between the initial and the post trafficking measurements. The decrease may also be due to evaporation or to a combination of the two factors. The moisture content increase in the outdoor loamy sand and FERF loam is likely due to the soil retaining its moisture while being compacted; the apparent moisture content percent increases with compaction, but the weight of water in the soil remains the same. The increase in moisture content of the mowed grass treatments in the outdoor loamy sand and FERF silty loam was greater than the unmowed grass treatments. In the FERF sand, the mowed grass treatment had a greater decrease in moisture content near the surface $(5 \mathrm{~cm})$ than the unmowed grass. Overall, soil conditions in the mowed grass treatments were impacted more than in the unmowed grass treatments.
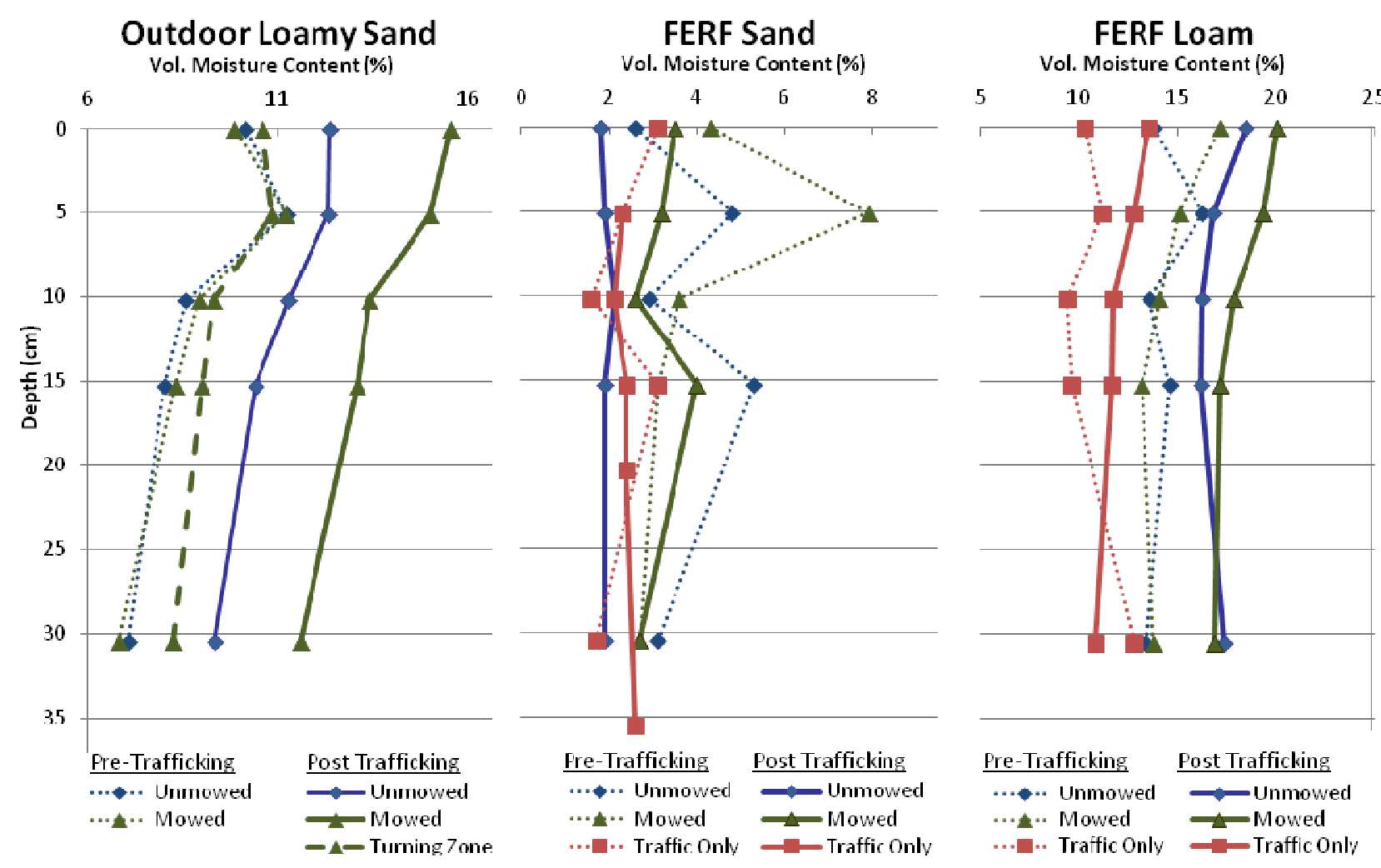

Figure 6. Moisture contents of test soils prior to trafficking (dotted lines) and post-trafficking (solid and dashed lines). Moisture contents increase with trafficking in the loamy soils both outdoors and in the FERF; the FERF sand soil loses moisture with trafficking. 


\subsubsection{Dry density}

On average, dry density measured using the drive cylinders was $2 \%$ higher than that measured using the nuclear gauge. However, since the nuclear gauge also provides moisture content data, only the nuclear gauge was used for measurements in the indoor section. In the near surface (top o-6 $\mathrm{cm}$ ) of the outdoor section, trafficking increased the dry density by approximately $20 \%$ in the unmowed grass section and $25 \%$ in the mowed grass section (Fig. 7). Data in the shear section (turning zone) is more variable; there the dry density increase ranged between 15 and $24 \%$.

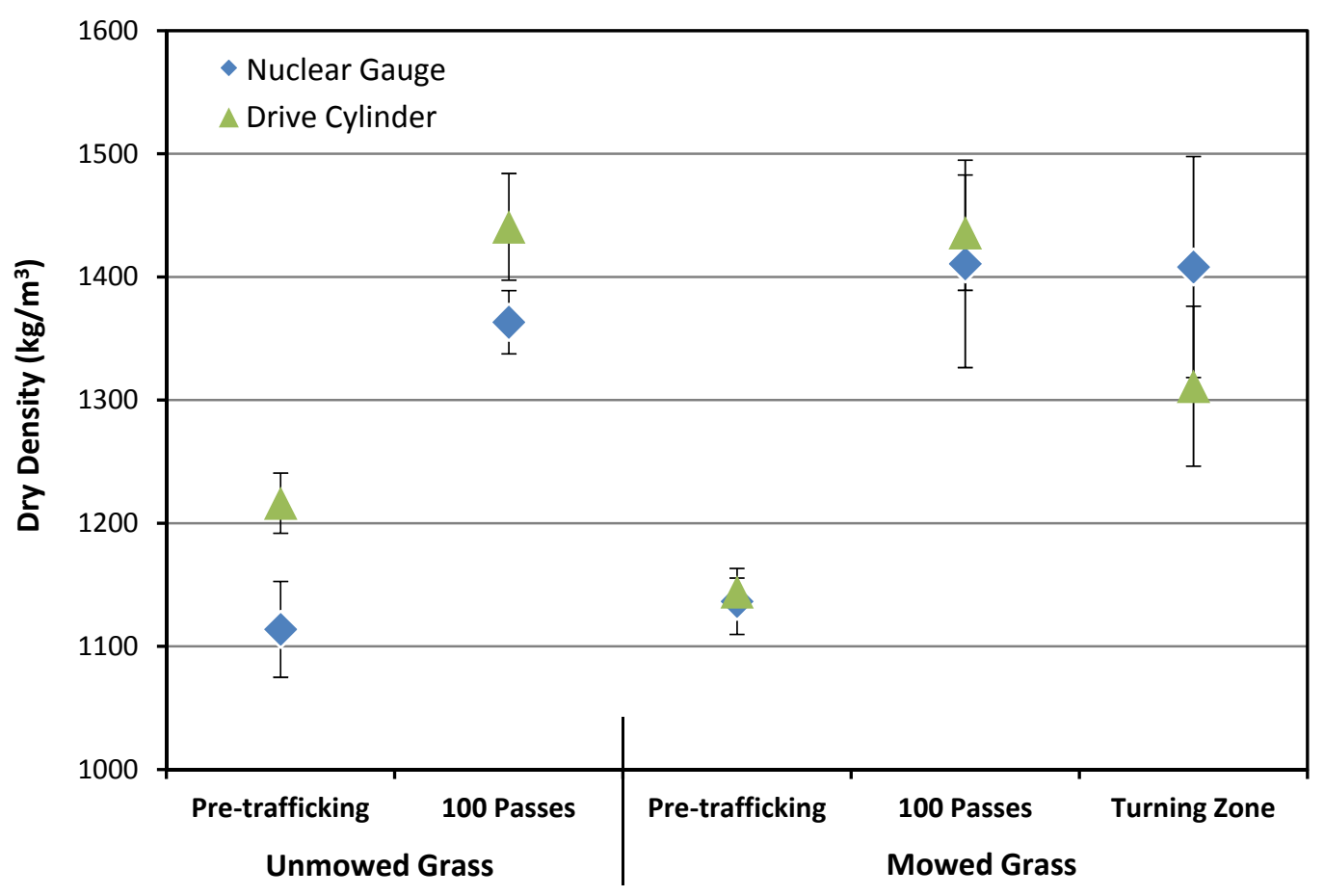

Figure 7. Comparison of dry density measurements using nuclear gauge and drive cylinder techniques at the surface for the outdoor test section.

For all test sections, trafficking, and thus soil compaction, increases the dry density of the soil both at the surface and at depth as shown by the results of the nuclear moisture/density gauge (Fig. 8). Density increase is most significant at the surface, but continues to a depth greater than 30 $\mathrm{cm}$. The density increase was greater in outdoor loamy sand and FERF silty loam soils than in the FERF sand soil. In the outdoor section, soil density in the mowed grass increased more than in the unmowed grass. The opposite was the case in the FERF for both the sand and loam soil types. This difference could be related to how long the grass treatments had been established. The unmowed grass of the outdoor section provided 
a mat that the vehicle drove across and little soil was exposed. The unmowed grass of the indoor loam section was shorter and not as thick, allowing the soil to be exposed more readily to the vehicle tires. A future biomass analysis from these experiments will provide additional insight.
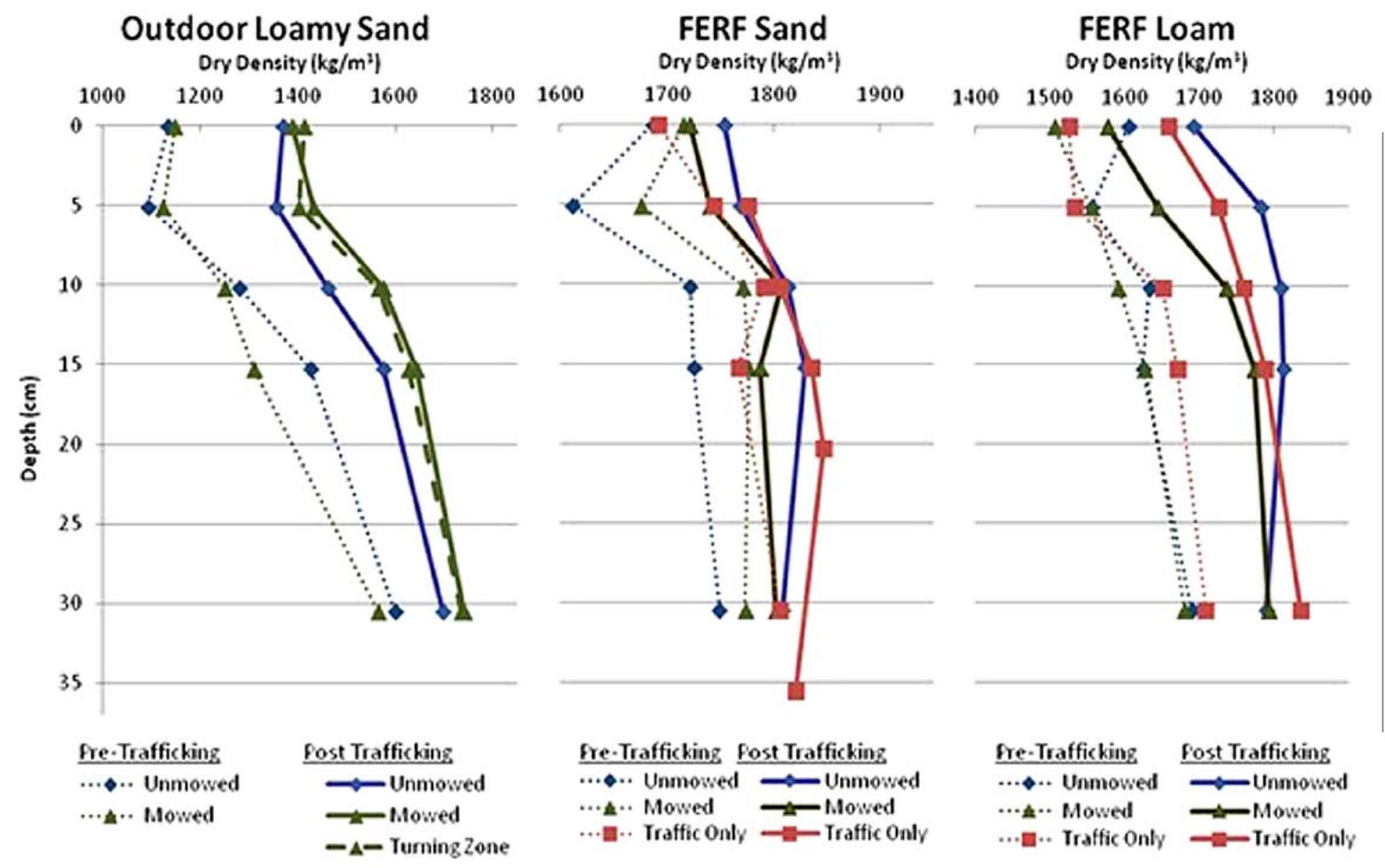

Figure 8. Dry density versus depth for all test sections and treatments. In all cases, density increases after trafficking.

\subsection{Soil strength}

\subsubsection{Outdoor test section}

As expected, heavy-vehicle trafficking increased soil strength in all test sections (Fig. 9). Cone index results show an increase in soil strength in the upper $15 \mathrm{~cm}$ with increasing vehicle traffic. Soil strength as measured by dynamic drop cone also increases for both treatments (mowed, unmowed) up to a peak around 75 passes, followed by a decrease at 100 passes. Soil strength in the turning zone, where the tires apply a greater shearing force, is lower than in the mowed grass straight section after 100 passes. The surface soil strength of the unmowed treatment increased more steeply than the mowed grass and remained slightly higher after 100 passes. The increases in soil strength are likely due to compaction. Decrease in near-surface soil strength at or near the end of testing may result from tire lugs breaking up the soil surface, including the root structure. 

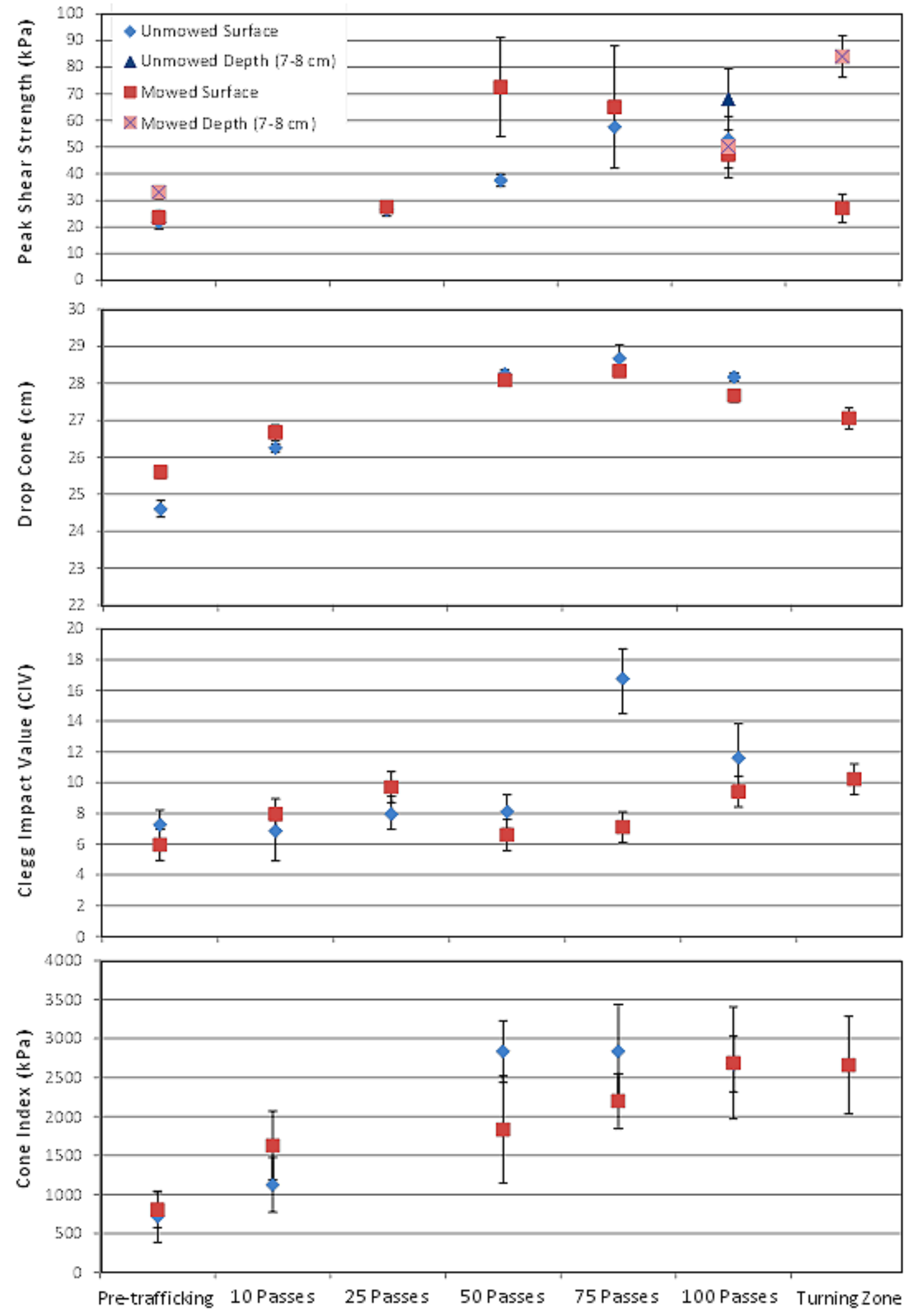

Figure 9. Strength indices for outdoor loamy sand. Data shown for the turning zone were measured after 100 passes. 
Similar to soil strength, shear strength initially increases substantially with trafficking, then decreases with additional trafficking as the soils become more deformed and vegetation is significantly impacted. As seen in the upper graph of Figure 9, shear strength in the mowed grass treatment increases dramatically between 25 and 50 passes, then decreases with additional passes. In the unmowed grass treatment, it increases more slowly, peaks at 75 passes, and then decreases. Surface shear strength in the turning zone after 100 passes is similar to the pre-trafficking shear strength. The shear strength at depth increases substantially after 100 passes and most dramatically in the turning zone where the soil is exposed to combined vertical and shear loading. Similar to the strength indices, the shear strength increases are likely due to compaction, and as the sections become significantly impacted at the surface by tire lugs, shear strength decreases.

Cone index measurements taken at depth show that soil strengthening continues to the maximum depth measured by the cone penetrometer (Fig. 10). The profiles end when the cone penetrometer could no longer be pushed into the soil. Soil strength in the mowed grass section is higher at depth than in the unmowed section. However, surface soil strength of the unmowed section increases more substantially after 50 passes than in the mowed section. 


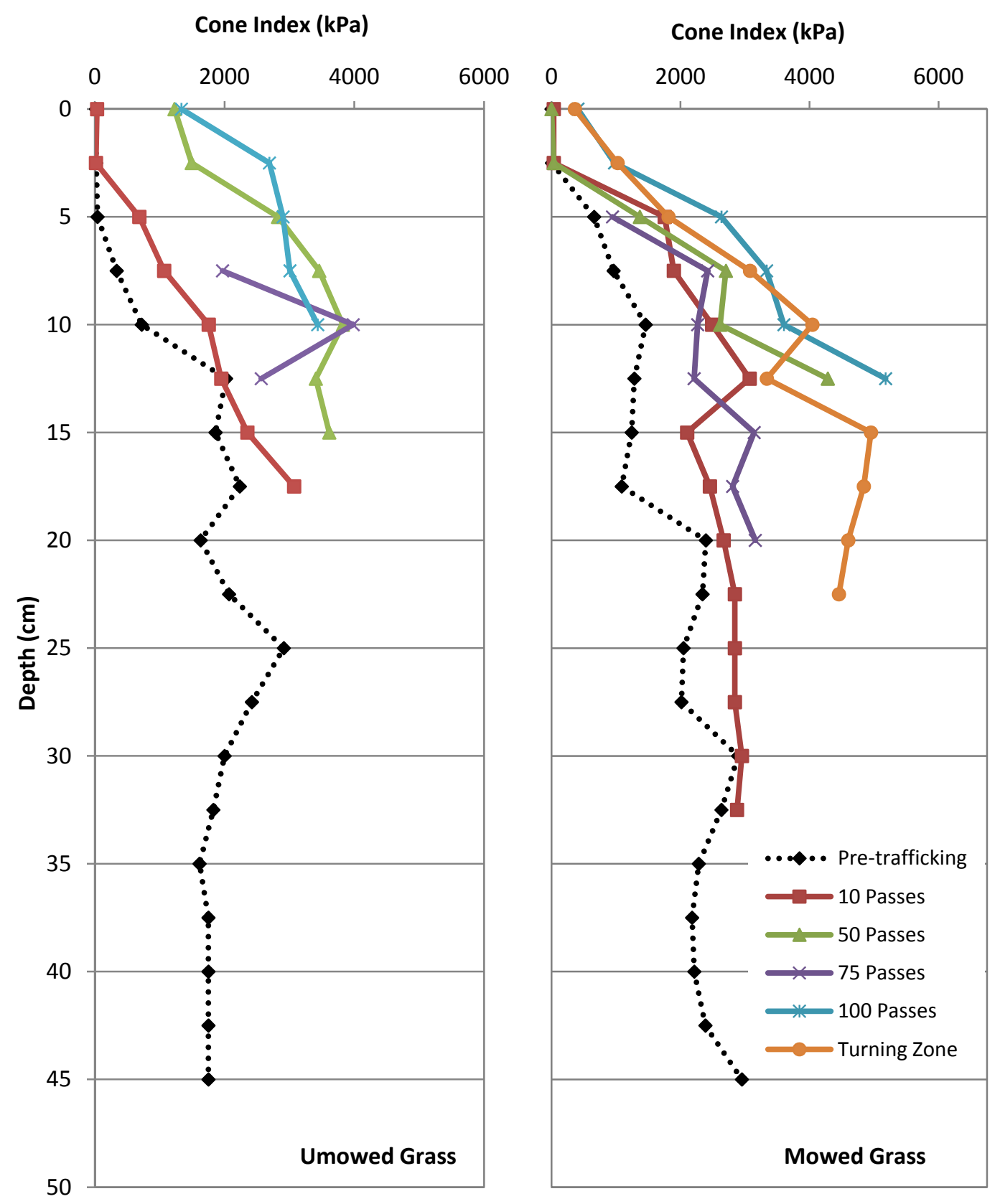

Figure 10. Cone index soil strength profiles for the outdoor unmowed (left) and mowed test sections (data presented are the averages of all readings in the section at that number of passes).

\subsubsection{FERF test section}

Trends in soil strength measured in the FERF silty loam test section were similar to the outdoor loamy sand test section (Fig. 11 and 12). In the near surface measurements, soil and shear strength initally increased, then either lessened the rate of increase or decreased in strength. The traffic 
only (bare soil) and unmowed grass treatments show the highest strength indices both before and after trafficking.

Soil strength in the sand section did not increase as substantially as in the silty loam section. The response to trafficking in all vegetation treatments was similar with little difference in the strength indexes. Shear strength measurements of the rut walls taken after 10 passes in sand section show that the soil immediately adjacent to the rut has a lower shear strength than prior to trafficking (Fig. 12). In the loam section, the shear strength in the rut walls is higher than pre-trafficking, but lower than the base of the ruts.
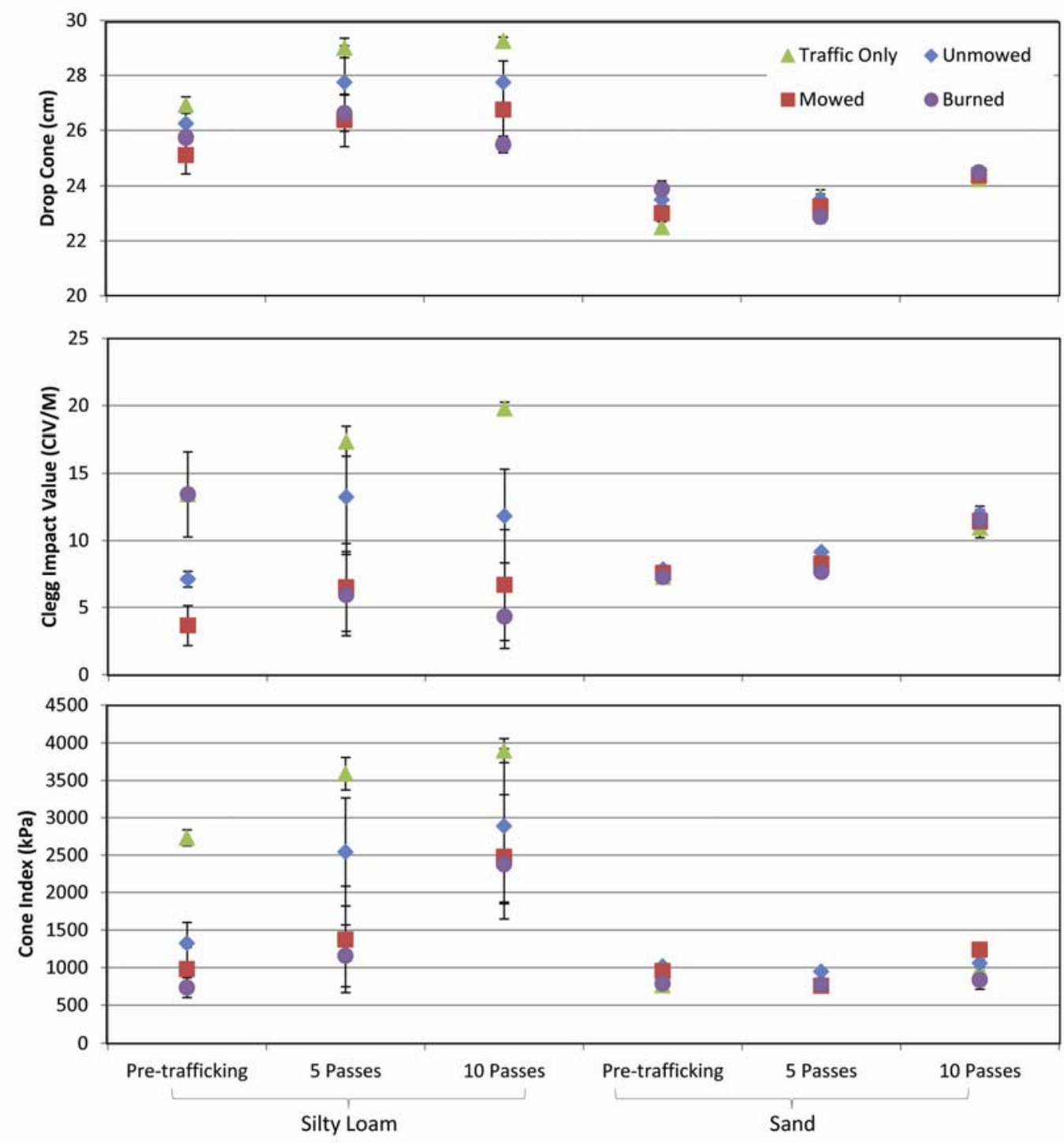

Figure 11. Strength indices for the FERF test sections. 


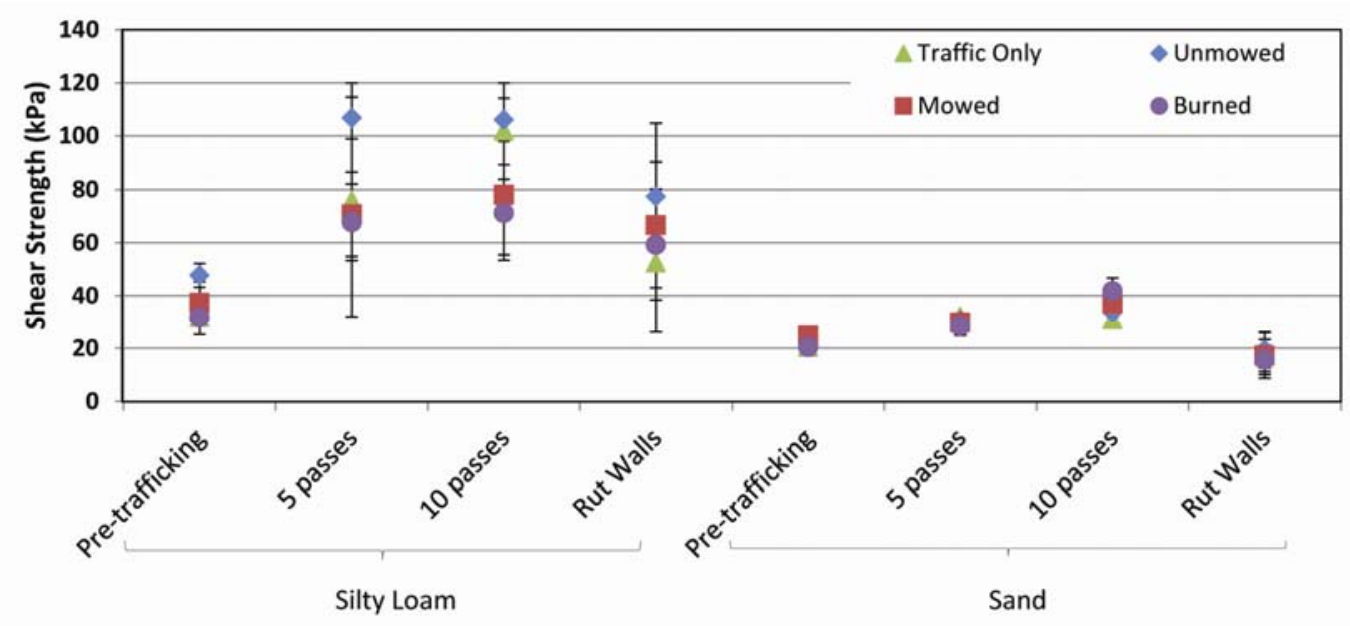

Figure 12. Shear strength for the FERF test sections.

\subsection{Terrain disturbance}

\subsubsection{Outdoor test section}

The impact severity based on the guidelines in Table 4 was measured after trafficking the outdoor section (Fig. 13). Trafficking had little impact on vegetation in the unmowed grass section; thus, the impact would be classified as imprint and pile according to Haugen et al. (2002). The impact was more severe in the mowed grass section, with a pile and combined classification between imprint and scrape. Trafficking impact was most severe in the shear (turning) zone. The impact severity categories mirror the decrease in drop cone index and shear strength observed in the mowed section and shear zone. The less severe ratings in the unmowed section also compare well with the lower decrease in drop cone indices and shear strength measured in that section.

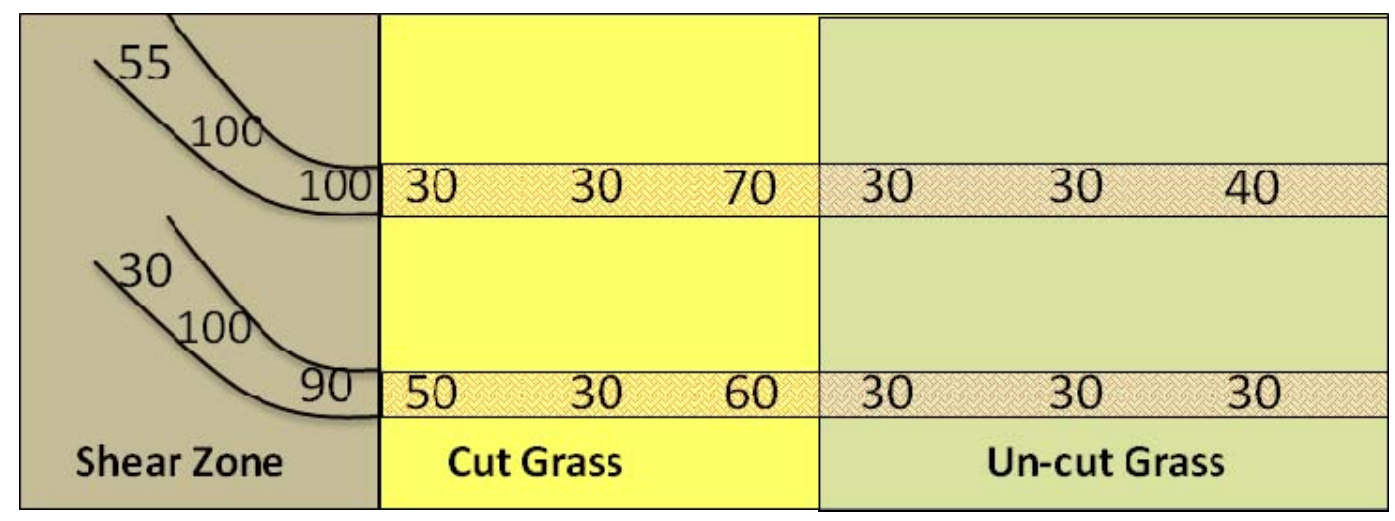

Figure 13. Outdoor section impact severity index results. 
Rut depths in the outdoor loam test section were highest for the mowed grass treatment reaching an average maximum depth of $9 \mathrm{~cm}$ with an average maximum pile height of $3 \mathrm{~cm}$ after 100 passes in the straight trafficking section (Fig. 14). Rut depths in the mowed grass straight trafficking section were on average $2 \mathrm{~cm}$ deeper than in the unmowed grass section. Rut depths in the turning zone were slightly higher than the straight section. Rut depths increased substantially from the first pass to 25 passes then increased much more gradually as the soil density and strength increased.

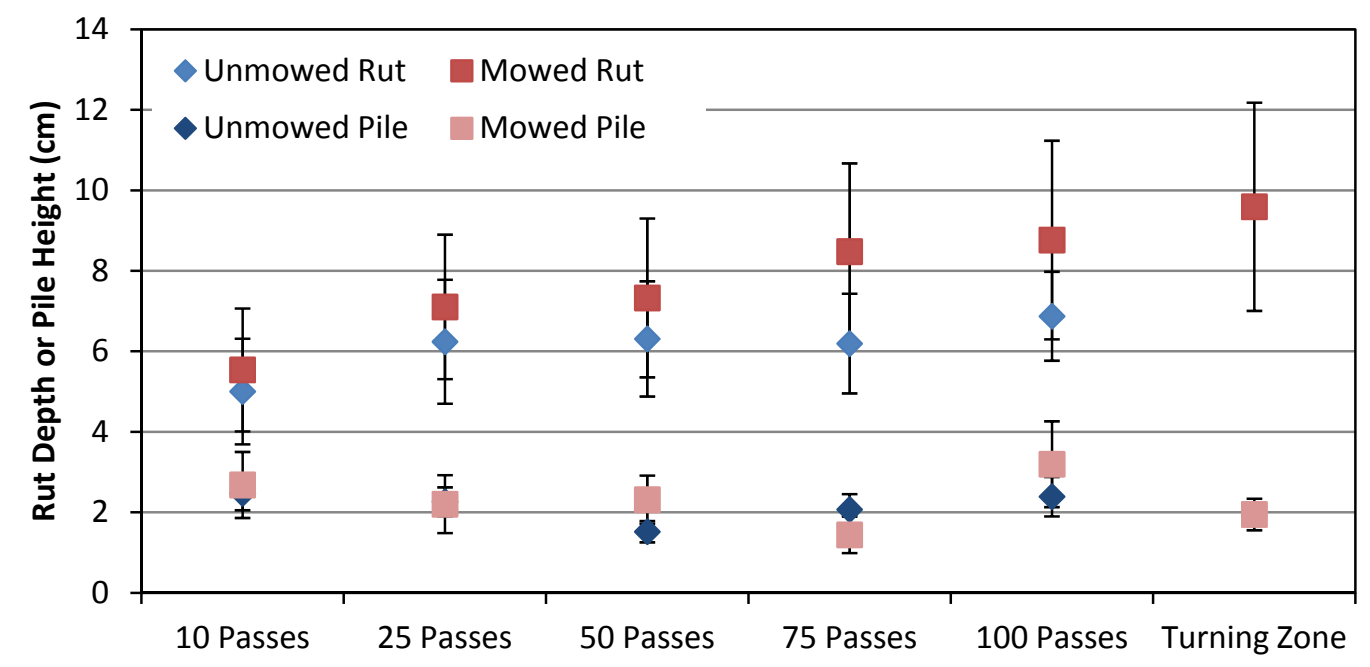

Figure 14. Outdoor loam rut depths and pile heights. Turning zone data were collected at 100 passes.

\subsubsection{FERF test section}

Similar to the outdoor section, the impact severity was measured for all vegetated sections in the FERF (Fig. 15). Trafficking impact was more substantial on the silty loam section than on the sand section. All test sections showed significant imprint and pile and, with the exception of the umowed grass treatment in the sand section, all test areas had some scrape and would be classified as combination according to Haugen et al. (2002). In both soil types, the unmowed grass treatment performed better than the mowed grass treatment and the burned grass treatment had the worst performance. Moreover, the burned section in the silty loam had the highest severity index score and also experienced a significant decrease in surface soil strength indices. If the tire lugs are breaking up the surface of the soil, one would expect that the section would have lower strength and a higher impact severity than an intact surface. 

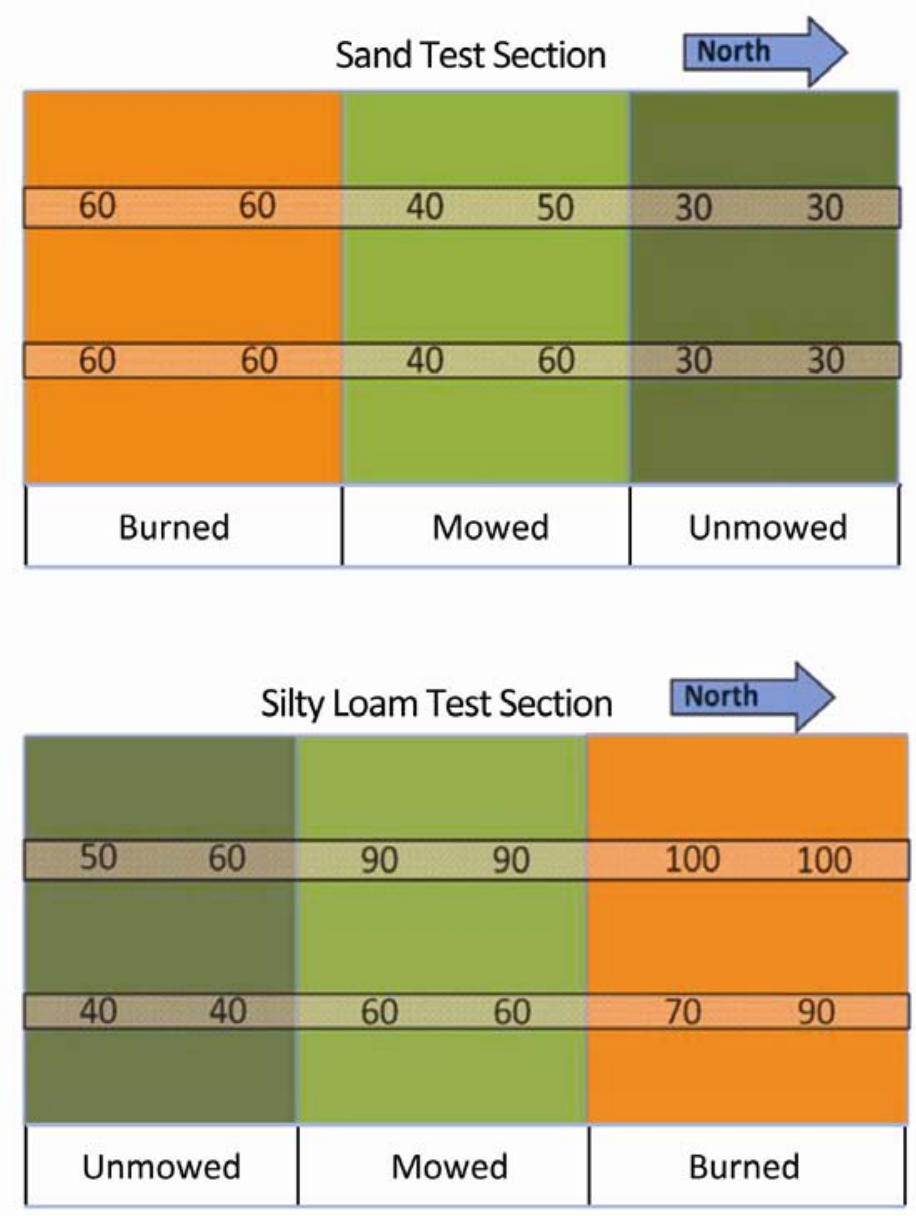

Figure 15. FERF Section impact severity index results.

Rut depths in the FERF silty loam test section reached an average maximum of $14 \mathrm{~cm}$ with similar corresponding pile heights (Fig. 16). Ruts were the deepest in the burned and mowed grass treatment sections and shallower in the unmowed grass and traffic only sections. Rut depths in the FERF sand test section were similar with the exception of the burned treatment area, which had substantially deeper ruts. This may unfortunately be attributed to the test bed layout with the burned sand test bed adjacent to the silty loam test bed where substantial rutting occurred. Similarly, rut depths in the trafficked only sections may also be affected by the test bed layout. The trafficked only sections are shorter and directly adjacent to the concrete pad surrounding the test bed. 

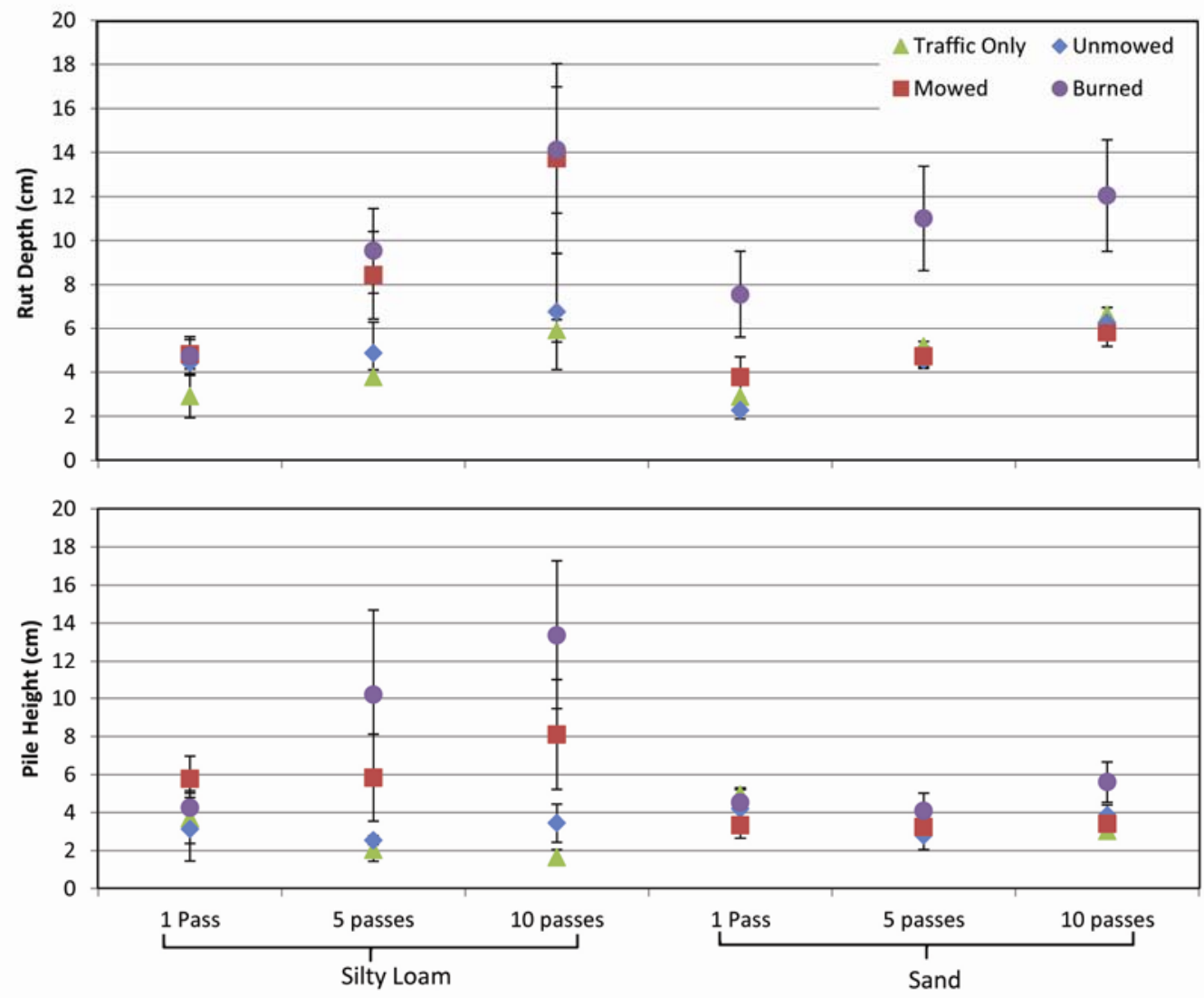

Figure 16. FERF rut depths and pile heights. 


\section{Conclusions}

The Army has shifted its training lands management strategy from a compliance-based strategy to a sustainability-based strategy. In an effort to support this shift, we have completed the first year of a four-year project investigating the impacts of military vehicle trafficking on vegetated soils subjected to different land management treatments so that sustainable land management strategies may be developed for future implementation. This study focuses specifically on the effects of military vehicle trafficking on soil conditions, soil strength, and terrain disturbance. Field and controlled experiments show that soil density and strength in vegetated soils increase as the surface is compacted by heavy vehicle trafficking. As the surface continues to see trafficking, the tire lugs dig up the surface causing a greater impact severity index and decreasing soil strength at and near the surface. Land management treatments change the degree that soils are impacted by trafficking. After trafficking, soil strengths in the mowed and burned sections were typically lower than in the unmowed sections. However, mobility parameters analyzed in a separate report will likely show decreased mobility over unmowed sections. Tradeoffs between mobility and trafficability within vegetated treatments will need to be further assessed to provide input into future land management strategies.

The results from this study, by themselves, do not provide sufficient insight into the effects of land management treatments on trafficability. Year two of the project involves assessing the recovery of those soils tested in year one. Follow-on work will include relating soil strength characteristics to biomass, determining how different land management strategies affect mobility and recovery from trafficking over time, and optimizing the NATO Reference Mobility Model to include the experimental results. 


\section{References}

Affleck, R. 2005. Disturbance measurements from off-road vehicles on seasonal terrain. ERDC/CRREL Technical Report TR-05-12. Hanover, NH: U.S. Army Engineer Research and Development Center, Cold Regions Research and Engineering Laboratory.

Anderson, A. B., A. J. Palazzo, P. D. Ayers, J. S. Fehmi, S. A. Shoop, P. Sullivan. 2005. Assessing the impacts of military vehicle traffic on natural areas. Introduction to the special issue and review of the relevant military vehicle impact literature. J ournal of Terramechanics 42: 143-158.

Goodwin, R. J., N. I. Warner, and D. L. O. Smith. 1991. The development of a dynamic dropcone device for the assessment of soil strength and the effects of machinery traffic. J ournal of Agricultural Engineering Research 48: 123-131.

Haugen, L. B., P. D. Ayers, A. B. Anderson, and P. E. Nissen. 2002. Using GPS to evaluate movement patterns and impacts during training maneuvers. In: Proceedings of the 14th International Society for Terrain-Vehicle Systems (ISTVS) Vicksburg, Mississippi.

Shoop, S., T. Cary, L. Barna, N. Buck, H. Howard. 2010. Experimental program for the assessment of vegetation effects on soil strength and trafficability. In: Proceedings of the J oint 9th Asia-Pacific ISTVS Conference and Annual Meeting of J apanese Society for Terramechanics. Sapporo, Japan, September 27 to 30, 2010. 


\section{Appendix A: Profilometer Analysis MATLAB Code}

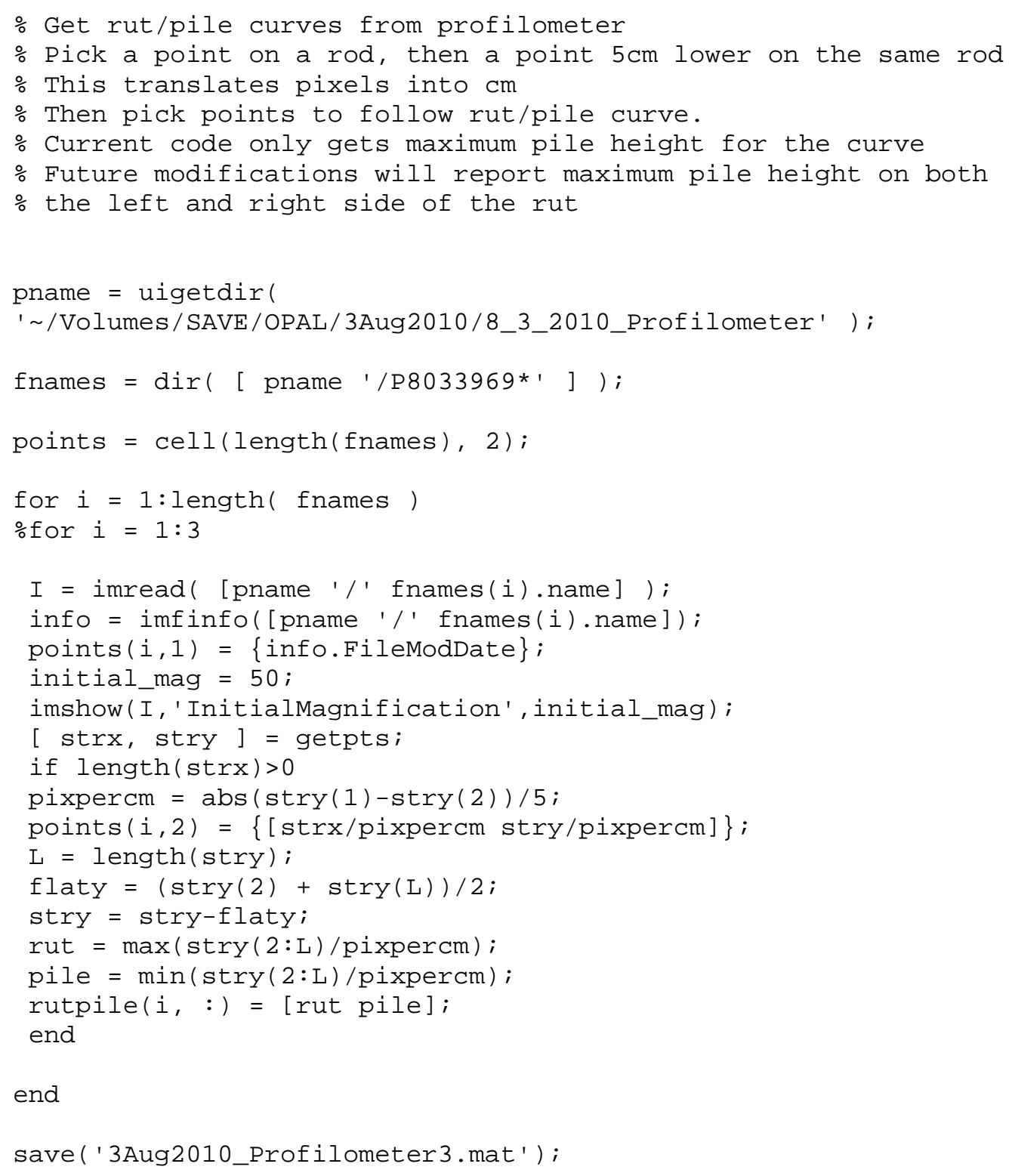




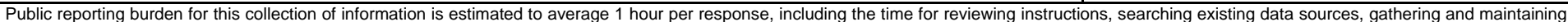

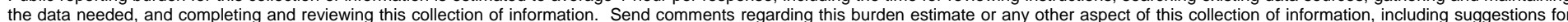

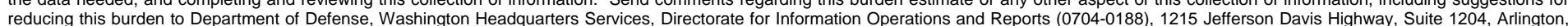

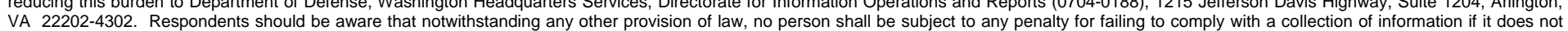
display a currently valid OMB control number. PLEASE DO NOT RETURN YOUR FORM TO THE ABOVE ADDRESS.
1. REPORT DATE (DD-MM-YYYY)
August 2012

\section{TITLE AND SUBTITLE}

Initial Effects of Heavy Vehicle Trafficking on Vegetated Soils
3. DATES COVERED (From - To)

5a. CONTRACT NUMBER

5b. GRANT NUMBER

5c. PROGRAM ELEMENT NUMBER

5d. PROJECT NUMBER

5e. TASK NUMBER

5f. WORK UNIT NUMBER

8. PERFORMING ORGANIZATION REPORT NUMBER

ERDC/CRREL TR-12-6

Cold Regions Research and Engineering Laboratory

U.S. Army Engineer Research and Development Center

72 Lyme Road

Hanover, NH 03755

\section{SPONSORING / MONITORING AGENCY NAME(S) AND ADDRESS(ES)}

U.S. Army Corps of Engineers Engineering Research and Development Center, Optimal Allocation of Land for Training and Non-Training Uses (OPAL) Program
10. SPONSOR/MONITOR'S ACRONYM(S)

11. SPONSOR/MONITOR'S REPORT NUMBER(S)

\section{DISTRIBUTION / AVAILABILITY STATEMENT}

Approved for public release; distribution is unlimited.

\section{SUPPLEMENTARY NOTES}

\section{ABSTRACT}

Numerous studies have investigated the effects of vehicle trafficking on terrain and how soils and soil conditions affect the mobility of military vehicles. However, the majority of these studies were conducted on non-vegetated soils. The purpose of our four-year study is to investigate the effects of heavy vehicle trafficking on vegetated soils and to assess the impacts of vegetation, specifically grass, on vehicle mobility. The research program includes a series of experiments assessing the effects of trafficking, mowing, and burning on vegetated soil strength. Three test sections were constructed and planted with perennial ryegrass: one section represented outdoor field conditions and two were controlled indoor sections (sand and silty loam). Mobility parameters of motion resistance and traction were collected in each test section prior to trafficking by a large military vehicle (HEMTT). Before and after trafficking, each test section was characterized including soil strength, moisture content, soil density, and terrain disturbance. The results show that vegetation affects soil strength and thus the terrain impacts of trafficking. Additionally, treatment of the vegetation affects soil strength, especially in silty loam soils. This paper summarizes the first year results regarding soil condition, soil strength, and vehicle impact severity. Future years will assess the recovery of the vegetation in the tested areas with the ultimate goal of making recommendations for the treatment of vegetated military training lands.

\section{SUBJECT TERMS}

Military training lands

Soil shear strength

16. SECURITY CLASSIFICATION OF:

\section{a. REPORT}

U

a. REPORT
$\mathrm{U}$

U

\section{Soil strength}

Trafficking

Vehicle impact severity b. ABSTRACT c. THIS PAGE

\begin{tabular}{|c|c|}
\hline $\begin{array}{c}\text { 17. LIMITATION } \\
\text { OF ABSTRACT }\end{array}$ & $\begin{array}{c}\text { 18. NUMBER } \\
\text { OF PAGES }\end{array}$ \\
\cline { 3 - 3 } & 35 \\
\hline
\end{tabular}

Vehicle mobility

19a. NAME OF RESPONSIBLE PERSON

19b. TELEPHONE NUMBER (include area code) 